\title{
Applications of Mathematics
}

\section{Zdeněk Milka}

Finite element solution of a stationary heat conduction equation with the radiation boundary condition

Applications of Mathematics, Vol. 38 (1993), No. 1, 67-79

Persistent URL: http://dml.cz/dmlcz/104535

\section{Terms of use:}

(C) Institute of Mathematics AS CR, 1993

Institute of Mathematics of the Czech Academy of Sciences provides access to digitized documents strictly for personal use. Each copy of any part of this document must contain these Terms of use.

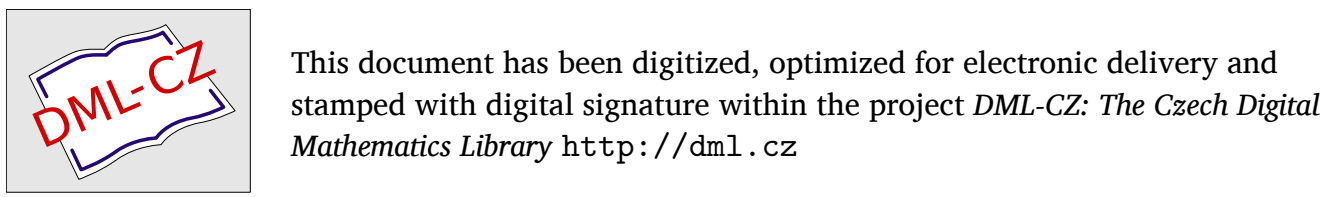




\title{
FINITE ELEMENT SOLUTION \\ OF A STATIONARY HEAT CONDUCTION EQUATION WITH THE RADIATION BOUNDARY CONDITION
}

\author{
ZDENĚK Milka, Praha
}

(Received June 8, 1992)

\begin{abstract}
Summary. In this paper we present a weak formulation of a two-dimensional stationary heat conduction problem with the radiation boundary condition. The problem can be described by an operator which is monotone on the convex set of admissible functions. The relation between classical and weak solutions as well as the convergence of the finite element method to the weak solution in the norm of the Sobolev space $H^{1}(\Omega)$ are examined.
\end{abstract}

Keywords: heat conduction, heat radiation, finite elements

AMS classification: $65 \mathrm{~N} 30$

\section{Formulation of the Problem}

Let $\Omega \subset \mathbb{R}^{2}$ be a bounded domain with a Lipschitz boundary $\Gamma$. The stationary heat conduction equation is

$$
-\operatorname{div}(\lambda \operatorname{grad} u)=f
$$

where $u$ is the temperature, $u \in C^{2}(\Omega) \cap C^{1}(\bar{\Omega}), u \geqslant 0$, since the temperature is measured in Kelvin's scale, $\lambda$ is a symmetric positive definite matrix of heat conduction coefficients, $\lambda \in\left(C^{1}(\bar{\Omega})\right)^{2 \times 2}, f \in L_{2}(\Omega)$ is the volume heat energy.

Let $\Gamma_{1}, \Gamma_{2}$ be relatively open sets in $\Gamma, \Gamma_{1} \cap \Gamma_{2}=\emptyset, \overline{\Gamma_{1}} \cup \overline{\Gamma_{2}}=\Gamma$. We prescribe boundary conditions

$$
\begin{aligned}
u=g & \text { on } \Gamma_{1}, \\
-\nu^{\top} \lambda \operatorname{grad} u=\alpha u+\beta u^{4} & \text { on } \Gamma_{2},
\end{aligned}
$$


where $g$ is the temperature prescribed on $\Gamma_{1}, g \geqslant 0, g \in H^{1}(\Omega), \nu$ is the outward unit normal to $\Gamma, \alpha \geqslant 0$ is the coefficient of convective heat transfer on $\Gamma_{2}, \alpha \in L_{\infty}\left(\Gamma_{2}\right)$, where, in the case $\Gamma_{1}=\emptyset$, we suppose $\alpha>0$ on a nonempty open subset of $\Gamma, \beta \geqslant 0$ is the coefficient of radiation heat transfer on $\Gamma_{2}, \beta \in L_{\infty}\left(\Gamma_{2}\right)$.

The boundary condition on $\Gamma_{2}$ is called the Stefan-Boltzmann condition. The function $u$, which statisfies the above conditions, is called the classical solution of the problem (1.1)-(1.2).

There exist many different methods how to treat analytically and numerically the Stefan-Boltzmann condition, see e.g. $[1,3,6,7,10,12,13,15,16]$. In the present paper, we slightly modify a variational approach, which is briefly described in [14]. Then we will examine the associated finite element approximations.

Let us set

$$
V=\left\{v \in H^{1}(\Omega) \mid v=0 \text { on } \Gamma_{1}\right\}
$$

where $H^{1}(\Omega)$ is the standard Sobolev space with the norm $\|\cdot\|_{1,2}$ and the seminorm ||$_{1,2}$. Multiplying (1.1) by an arbitrary function $v \in V$ and integrating over $\Omega$ we obtain from Green's theorem:

$$
\int_{\Omega} \lambda \operatorname{grad} u \cdot \operatorname{grad} v \mathrm{~d} x-\int_{\Gamma_{2}}\left(\nu^{\top} \lambda \operatorname{grad} u\right) v \mathrm{~d} s=\int_{\Omega} f v \mathrm{~d} x \quad \forall v \in V .
$$

Employing the boundary conditions (1.2), we get

$$
\int_{\Omega} \lambda \operatorname{grad} u \cdot \operatorname{grad} v \mathrm{~d} x+\int_{\Gamma_{2}}\left(\alpha u+\beta u^{4}\right) v \mathrm{~d} s=\int_{\Omega} f v \mathrm{~d} x \quad \forall v \in V .
$$

So every classical solution of (1.1)-(1.2), if it exists, satisfies the equation (1.3).

Now we shall show that all integrals in (1.3) are well-defined even for $u, v$ from $H^{1}(\Omega)$. This is clear for the first and the third ones. The following theorem is presented in $[11$, p. 86$]$ :

Theorem 1.1. Let $\Omega \subset \mathbb{R}^{2}$ be a bounded domain with a Lipschitz boundary. Then for every real number $q \geqslant 1$ there exists a single continuous linear mapping $Z$ : $H^{1}(\Omega) \rightarrow L_{q}(\Gamma)$ which satisfies $Z v=v$ on $\Gamma$ for all $v \in C^{\infty}(\bar{\Omega})$.

From Theorem 1.1 we see that the second integral in (1.3) is also well-defined for arbitrary $u, v \in H^{1}(\Omega)$.

For the sake of simplicity set

$$
a(v, w)=\int_{\Omega} \lambda \operatorname{grad} v \cdot \operatorname{grad} w \mathrm{~d} x+\int_{\Gamma_{2}} \alpha v w \mathrm{~d} s, \quad b(v)=\int_{\Omega} f v \mathrm{~d} x .
$$


Now the equation (1.3) can be rewritten as

$$
a(u, v)+\int_{\Gamma_{2}} \beta u^{4} v \mathrm{~d} s=b(v) \quad \forall v \in V .
$$

Let us define

$$
U=\left\{v \in H^{1}(\Omega) \mid v \geqslant 0 \text { in } \Omega, v=g \text { on } \Gamma_{1}\right\}
$$

The set $U$ is called the sel of admissible functions. Note that $U$ is convex and closed with respect to the norm $\|\cdot\|_{1,2}$.

Definition 1.2. Let $\Omega \subset \mathbb{R}^{2}$ be a bounded domain with a Lipschitz boundary. A function $u_{0} \in U$ is called a weak solution of the problem (1.1)-(1.2) if

$$
a\left(u_{0}, v-u_{0}\right)+\int_{\Gamma_{2}} \beta u_{0}^{4}\left(v-u_{0}\right) \mathrm{d} s \geqslant b\left(v-u_{0}\right) \quad \forall v \in U .
$$

For the functions $u_{0}$ and $v \in U$ we have $v-u_{0} \in V$. So the condition (1.5) is weaker than that in (1.4).

Consider the functional

$$
\mathrm{II}(v)=\frac{1}{2} a(v, v)+\frac{1}{5} \int_{\Gamma_{2}} \beta v^{5} \mathrm{~d} s-b(v) .
$$

By Theorem 1.1 this functional is well-defined and continuous in $H^{1}(\Omega)$. Moreover, $\Pi$ is clearly $G$-differentiable, strictly convex and coercive in $U$. That is why there exists precisely one element $\bar{u} \in U$ in which $\Pi$ attains its minimum over the set $U$. This element fulfils

$$
\operatorname{DII}(\bar{u} ; v-\bar{u}) \geqslant 0 \quad \forall v \in U
$$

where

$$
\operatorname{D\Pi }(v ; w)=a(v, w)+\int_{\Gamma_{2}} \beta v^{4} w \mathrm{~d} s-b(w)
$$

is the Gateaux derivative of $\mathrm{Il}$ at the point $v$ in the direction $w$. We see the inequality (1.7) is the same as that in (1.5), so $\bar{u}$ is the only solution of (1.1)-(1.2) in the sense of Definition 1.2 . 


\section{Some Properties of THE WEAK SOLUTION}

It is clear that a classical solution is also a weak solution. Now we shall formulate conditions ensuring that the weak solution is the classical one.

Definition 2.1. The set $\Gamma_{1}$ is said to possess the property $(K)$ if it is the union of a finite number of comnected and relatively open sets in $\Gamma$ such that their closures are disjoint.

Let us set

$$
\Omega_{\delta}^{\prime}=\left\{x \in \mathbb{R}^{2} \mid \text { dist }\left(\Gamma_{1}, x\right)<\delta\right\}, \Omega_{\delta}=\Omega_{\delta}^{\prime} \cap \Omega
$$

The next lemma follows from a more general proposition which is presented in [4, p. 618].

Lemma 2.2. Let $\Gamma_{1}$ have the property (K). Then for an arbitrary function $u \in V$ there exists a sequence of functions $\left\{v_{n}\right\} \subset V \cap C^{\infty}(\bar{\Omega})$ such that $v_{n} \rightarrow v$ in the norm of $H^{1}(\Omega)$ and $v_{n}=0$ on $\Omega_{\frac{1}{n}}$.

For an arbitrary real constant $r>0$ define

$$
W(r)=\left\{v \in C^{\infty}(\bar{\Omega}) \mid\|v\|_{C(\bar{\Omega})} \leqslant r, v=0 \text { on } \Gamma_{1}\right\}
$$

Theorem 2.3. Let $\Gamma_{1}$ have the property $(\mathrm{K})$ and let $u_{0}$ be the weak solution of (1.1)-(1.2). Let $u_{0} \in C^{2}(\Omega) \cap C^{1}(\bar{\Omega})$ and let there exist a constant $C_{u_{0}}>0$ such that $u_{0} \geqslant C_{u_{0}}$ holds in the domain $\Omega$. Then $u_{0}$ is also the classical solution of (1.1)-(1.2).

Pro of. The weak solution $u_{0} \in U$ satisfies the condition

$$
\operatorname{DII}\left(u_{0} ; w-u_{0}\right) \geqslant 0 \quad \forall w \in U
$$

For every function $v \in W\left(C_{u_{0}}\right)$ we have $u_{0}+v \in U, u_{0}-v \in U$. Therefore

$$
\operatorname{D\Pi }\left(u_{0} ; u_{0}+v-u_{0}\right)=\operatorname{D\Pi }\left(u_{0} ; v\right) \geqslant 0, \quad \operatorname{D\Pi }\left(u_{0} ; u_{0}-v-u_{0}\right)=\operatorname{D\Pi }\left(u_{0} ;-v\right) \geqslant 0 .
$$

From linearity of $\operatorname{D\Pi }\left(u_{0} ;\right.$. ) and density of $V \cap C^{\infty}(\bar{\Omega})$ in $V$ (cf. Lemma 2.2) we have $\operatorname{D\Pi }\left(u_{0} ; v\right)=0$. Hence by $(1.8)$ we obtain

$$
a\left(u_{0}, v\right)+\int_{\Gamma_{2}} \beta u_{0}^{4} v \mathrm{~d} s=b(v)
$$


for all $v \in V$. From here we arrive at

$$
\begin{aligned}
-\int_{\Omega} \operatorname{div}\left(\lambda \operatorname{grad} u_{0}\right) v \mathrm{~d} x & =\int_{\Omega} f v \mathrm{~d} x \quad \forall v \in H_{0}^{1}(\Omega), \\
-\int_{\Gamma_{2}}\left(\nu^{\top} \lambda \operatorname{grad} u_{0}\right) v \mathrm{~d} s & =\int_{\Gamma_{2}}\left(\alpha u_{0}+\beta u_{0}^{4}\right) v \mathrm{~d} s \quad \forall v \in V .
\end{aligned}
$$

Since the space $H_{0}^{1}(\Omega)$ is dense in $L_{2}(\Omega)$ and traces of the functions from $V$ are dense in $L_{2}\left(\Gamma_{2}\right)$ (cf. [11, p. 87]), $u_{0}$ fulfils $(1.1)-(1.2)$.

Theorem 2.4. The weak solution $u_{0}$ of (1.1)-(1.2) depends continuously on the functions $\alpha, \beta$ a $f$.

Proof. Suppose there are two weak solutions $u_{i}$ of two problems given by functions $\alpha_{i}, \beta_{i}, f_{i}, i=0,1$. From the definition of the weak solution we have

$$
\begin{aligned}
& \int_{\Omega} \lambda \operatorname{grad} u_{0} \cdot \operatorname{grad}\left(u_{1}-u_{0}\right) \mathrm{d} x+\int_{\Gamma_{2}} \alpha_{0} u_{0}\left(u_{1}-u_{0}\right) \mathrm{d} s \\
& +\int_{\Gamma_{2}} \beta_{0} u_{0}^{4}\left(u_{1}-u_{0}\right) \mathrm{d} s \geqslant \int_{\Omega} f_{0}\left(u_{1}-u_{0}\right) \mathrm{d} x, \\
& \int_{\Omega} \lambda \operatorname{grad} u_{1} \cdot \operatorname{grad}\left(u_{0}-u_{1}\right) \mathrm{d} x+\int_{\Gamma_{2}} \alpha_{1} u_{1}\left(u_{0}-u_{1}\right) \mathrm{d} s \\
& +\int_{\Gamma_{2}} \beta_{1} u_{1}^{4}\left(u_{0}-u_{1}\right) \mathrm{d} s \geqslant \int_{\Omega} f_{1}\left(u_{0}-u_{1}\right) \mathrm{d} x .
\end{aligned}
$$

We multiply both inequalities by -1 , sum up and obtain

$$
\begin{aligned}
& \int_{\Omega} \lambda\left|\operatorname{grad}\left(u_{0}-u_{1}\right)\right|^{2} \mathrm{~d} x+\int_{\Gamma_{2}}\left(\alpha_{0} u_{0}-\alpha_{1} u_{1}\right)\left(u_{0}-u_{1}\right) \mathrm{d} s \\
& +\int_{\Gamma_{2}}\left(\beta_{0} u_{0}^{4}-\beta_{1} u_{1}^{4}\right)\left(u_{0}-u_{1}\right) \mathrm{d} s \leqslant \int_{\Omega}\left(f_{0}-f_{1}\right)\left(u_{0}-u_{1}\right) \mathrm{d} x .
\end{aligned}
$$

Using the relations

$$
\begin{gathered}
\alpha_{0} u_{0}-\alpha_{1} u_{1}=\alpha_{0} u_{0}-\alpha_{0} u_{1}+\alpha_{0} u_{1}-\alpha_{1} u_{1}=\alpha_{0}\left(u_{0}-u_{1}\right)+u_{1}\left(\alpha_{0}-\alpha_{1}\right), \\
\beta_{0} u_{0}^{4}-\beta_{1} u_{1}^{4}=\beta_{0} u_{0}^{4}-\beta_{0} u_{1}^{4}+\beta_{0} u_{1}^{4}-\beta_{1} u_{1}^{4}=\beta_{0}\left(u_{0}^{4}-u_{1}^{4}\right)+u_{1}^{4}\left(\beta_{0}-\beta_{1}\right),
\end{gathered}
$$

we have

$$
\begin{aligned}
& \int_{\Omega} \lambda\left|\operatorname{grad}\left(u_{0}-u_{1}\right)\right|^{2} \mathrm{~d} x+\int_{\Gamma_{2}} \alpha_{0}\left(u_{0}-u_{1}\right)^{2} \mathrm{~d} s \\
& +\int_{\Gamma_{2}}\left(\beta_{0}\left(u_{0}^{4}-u_{1}^{4}\right)+u_{1}^{4}\left(\beta_{0}-\beta_{1}\right)\right)\left(u_{0}-u_{1}\right) \mathrm{d} s \\
& \leqslant \int_{\Omega}\left(f_{0}-f_{1}\right)\left(u_{0}-u_{1}\right) \mathrm{d} x-\int_{\Gamma_{2}} u_{1}\left(\alpha_{0}-\alpha_{1}\right)\left(u_{0}-u_{1}\right) \mathrm{d} s .
\end{aligned}
$$


Since

$$
\beta_{0}\left(u_{0}^{4}-u_{1}^{4}\right)\left(u_{0}-u_{1}\right)=\beta_{0}\left(u_{0}-u_{1}\right)^{2}\left(u_{0}+u_{1}\right)\left(u_{0}^{2}+u_{1}^{2}\right) \geqslant 0
$$

for $u_{0}, u_{1} \in U$, we obtain from the foregoing inequality

$$
\begin{aligned}
& \int_{\Omega} \lambda\left|\operatorname{grad}\left(u_{0}-u_{1}\right)\right|^{2} \mathrm{~d} x+\int_{\Gamma_{2}} \alpha_{0}\left(u_{0}-u_{1}\right)^{2} \mathrm{~d} s \leqslant \int_{\Omega}\left|\left(f_{0}-f_{1}\right)\left(u_{0}-u_{1}\right)\right| \mathrm{d} x \\
& +\int_{\Gamma_{2}}\left|u_{1}\left(\alpha_{0}-\alpha_{1}\right)\left(u_{0}-u_{1}\right)\right| \mathrm{d} s+\int_{\Gamma_{2}} u_{1}^{4}\left|\left(\beta_{0}-\beta_{1}\right)\left(u_{0}-u_{1}\right)\right| \mathrm{d} s .
\end{aligned}
$$

Now we estimate the left-hand side by the Friedrichs inequality and the second and third terms on the right-hand side with help of Theorem 1.1. Then for a sufficiently large constant $C>0$ we have

$$
\left\|u_{0}-u_{1}\right\|_{1,2}^{2} \leqslant C\left(\left\|f_{0}-f_{1}\right\|_{0,2}+\left\|\alpha_{0}-\alpha_{1}\right\|_{0, \infty, \Gamma_{2}}+\left\|\beta_{0}-\beta_{1}\right\|_{0, \infty, \Gamma_{2}}\right)\left\|u_{0}-u_{1}\right\|_{1,2}
$$

where $C$ depends only on $u_{1}$.

\section{Solution of the variational formulation BY THE FINITE ELEMENT METHOD}

For simplicity we shall suppose that $\Omega \subset \mathbb{R}^{2}$ is a polygonal domain with a Lipschitz boundary and $\Gamma_{1}$ has the property $(K)$. Then $\bar{\Omega}$ can be divided in the sense of $[2$, p.38] into a finite number of closed triangles $K_{i}, i \in I$. Such a triangulation will be denoted by $T_{h}$, where $h=\max _{i \in I} \operatorname{diam} K_{i}$.

Consider a family of triangulations $\mathscr{F}=\left\{T_{h}\right\}, h \rightarrow 0+$. For a fixed $h$ the triangulation $T_{h}$ is formed by the triangles $K_{i}^{h}, i \in I^{h}$. Let us define

$$
X_{h}=\left\{v_{h} \in C(\bar{\Omega})\left|v_{h}\right|_{K_{i}^{h}} \in P_{1}\left(K_{i}^{h}\right) \forall i \in I^{h}\right\}
$$

The spaces $X_{h}$ contain functions continuous on $\bar{\Omega}$ and linear on each of $K_{i}^{h} \in T_{h}$. Moreover (cf. [9, p. 27]),

$$
X_{h} \subset H^{1}(\Omega) .
$$

Let $\pi_{h}: C(\bar{\Omega}) \mapsto X_{h}$ be the standard linear interpolation operator such that for all functions $v \in C(\bar{\Omega})$ we have $\pi_{h} v(x)=v(x)$ at the vertices $x$ of the triangles $K_{i}^{h}$, $i \in I^{h}$. 
For simplicity we shall suppose that the function $g$ occurring in the boundary conditions (1.2) and the chosen family of triangulations $\mathscr{F}$ satisfy

$$
\exists h_{0}>0 \forall h \in\left(0, h_{0}\right) g \in X_{h} .
$$

It means that the function $g$ is equal to its interpolation $\pi_{h} g$ for sufficiently small $h$.

For $h \in\left(0, h_{0}\right)$ let us define

$$
U_{h}=U \cap X_{h} .
$$

Clearly the sets $U_{h}$ are convex and closed. So for $h \in\left(0, h_{0}\right)$ there exists one and only one solution of the discrete problem

$$
\Pi\left(u_{h}\right)=\inf _{v_{h} \in U_{h}} \Pi\left(v_{h}\right) .
$$

Now our goal is to prove that under certain assumptions the solutions $u_{h}$ of the problems (3.3) tend to the weak solution of (1.1)-(1.2).

Definition 3.1. We say that a family of triangulations $\mathscr{F}$ satisfies the maximum angle condition if there exists an angle $\gamma<180^{\circ}$ such that every triangle $K_{i}^{h} \in T_{h} \in$ $\mathscr{T}$ has all its angles less or equal to $\gamma$.

In the paper [8, p. 225] it is proved:

Theorem 3.2. Let $\Omega \subset \mathbb{R}^{2}$ be a polygonal domain with a Lipschitz boundary, $\mathscr{F}$ a family of triangulations which fulfils the maximum angle condition. Then there exists a constant $C>0$ independent of h such that

$$
\left\|v-\pi_{h} v\right\|_{1,2} \leqslant C h|v|_{2,2} \quad \forall v \in H^{2}(\Omega) .
$$

For an arbitrary parameter $\varrho>0$ we denote by $R_{\varrho}$ the standard regularization operator which maps $L_{1}(\Omega)$ into $C^{\infty}(\bar{\Omega})($ cf. $[11$, p. 58$])$ :

$$
\left(R_{\varrho} v\right)(x)=\int_{|y|<\varrho} v(x+y) \omega(y, \varrho) \mathrm{d} y
$$

where we define $v=0$ outside $\Omega$ and where $\omega(y, \varrho)$ (the regularization kernel) is a smooth non-negative hill function defined in $\mathbb{R}^{2}$, which vanishes for $y$ such that $|y| \geqslant \varrho$ and fulfils

$$
\int_{|y|<\varrho} \omega(y, \varrho) \mathrm{d} y=1 .
$$


Recall that the sets $\Omega_{\delta}, \Omega_{\delta}^{\prime}$ were defined in (2.1).

Lemma 3.3. Let $\Omega \subset \mathbb{R}^{2}$ be a bounded domain with a Lipschitz boundary. Then for every $\delta>0$ there exists a function $\theta_{\delta} \in C^{\infty}(\bar{\Omega}), \theta_{\delta}=0$ in $\Omega_{\frac{\delta}{2}}, \theta_{\delta}=1$ in $\bar{\Omega}-\Omega_{\delta}$, $\theta_{\delta} \geqslant 0$ in $\Omega$.

Proof. Put $\tau=\frac{3}{4} \delta$. Let us define

$$
\begin{array}{ll}
\theta_{\delta}^{\prime}=0 & \text { for } x \in \Omega_{\tau}^{\prime}, \\
\theta_{\delta}^{\prime}=1 & \text { for } x \in \mathbb{R}^{2}-\Omega_{\tau}^{\prime} .
\end{array}
$$

If we choose $\varrho \in\left(0, \frac{\delta}{4}\right)$, we can take $\theta_{\delta}=R_{\varrho} \theta_{\delta}^{\prime}$.

The following lemma is to be found in $[5$, p. 25]:

Lemma 3.4. Let $\Omega \subset \mathbb{R}^{2}$ be a bounded domain with a Lipschitz boundary. For $v \in H^{1}(\Omega)$ define

$$
v^{+}=\max (0, v), \quad v^{-}=\max (0,-v) .
$$

Then the functions $v^{+}, v^{-}$belong to $H^{1}(\Omega)$ and the mapping $v \mapsto\left\{v^{+}, v^{-}\right\}$from $H^{1}(\Omega)$ into $H^{1}(\Omega) \times H^{1}(\Omega)$ is continuous.

Lemma 3.5. Let $\Omega \subset \mathbb{R}^{2}$ be a bounded domain with a Lipschitz boundary and $v, w \in H^{1}(\Omega)$. Let $\left\{v_{n}\right\} \subset H^{1}(\Omega)$ be a sequence of functions, $v_{n} \rightarrow v$ in $H^{1}(\Omega)$ and let

$$
\hat{v}=\max (v, w), \quad \hat{v}_{n}=\max \left(v_{n}, w\right) .
$$

Then $\hat{v}_{n} \rightarrow \hat{v}$ in the norm of the space $H^{1}(\Omega)$.

Proof.

$$
\begin{aligned}
\hat{v} & =\max (v, w)=\frac{1}{2}((v+w)+|v-w|), \\
\hat{v}_{n} & =\max \left(v_{n}, w\right)=\frac{1}{2}\left(\left(v_{n}+w\right)+\left|v_{n}-w\right|\right),
\end{aligned}
$$

Since $v_{n}-w \rightarrow v-w$, it follows from Lemma 3.4 that $\left|v_{n}-w\right| \rightarrow|v-w|$.

Lemma 3.6. Let $\Omega \subset \mathbb{R}^{2}$ be a domain. Let $\bar{\Omega} \subset \Omega_{1}$, where $\Omega_{1} \subset \mathbb{R}^{2}$ is a bounded domain, and let $v \in C\left(\overline{\Omega_{1}}\right)$. Then

$$
\lim _{\varrho \rightarrow 0}\left\|v-R_{\varrho} v\right\|_{C(\bar{\Omega})}=0 .
$$


Proof. The proof is similar to that in [11, p. 59], which deals with the case of convergence in the spaces $L_{p}(\Omega)$. For an arbitrary $x \in \Omega$ and $\varrho<\operatorname{dist}\left(\partial \Omega, \partial \Omega_{1}\right)$ we have

$$
\begin{aligned}
\left|v(x)-\left(R_{\varrho} v\right)(x)\right| & =\left|v(x)-\int_{|y|<\varrho} v(x+y) \omega(y, \varrho) \mathrm{d} y\right| \\
& =\left|\int_{|y|<\varrho}(v(x)-v(x+y)) \omega(y, \varrho) \mathrm{d} y\right| .
\end{aligned}
$$

The set $\overline{\Omega_{1}}$ is compact, so $v$ is uniformly continuous there. Then for every $\varepsilon>0$ there exists $\delta \in(0, \varepsilon)$ such that for arbitrary $x_{1}, x_{2} \in \Omega$ we get

$$
\left|x_{1}-x_{2}\right|<\delta \Rightarrow\left|v\left(x_{1}\right)-v\left(x_{2}\right)\right|<\varepsilon .
$$

For $\varrho<\frac{\delta}{2}$ this yields

$$
\left|v(x)-\left(R_{\varrho} v\right)(x)\right|<\varepsilon .
$$

Theorem 3.7. Let $\Omega \subset \mathbb{R}^{2}$ be a polygonal domain with a Lipschitz boundary. Let $\mathscr{F}$ be a family of triangulations which satisfies the maximum angle condition, and let (3.2) hold. Then for all $v \in U$ there exists a sequence of functions $\left\{v_{h}\right\}$, $v_{h} \in U_{h}$, such that

$$
\lim _{h \rightarrow 0}\left\|v-v_{h}\right\|_{1,2}=0
$$

Proof. The proof is a modified version of the proof of a similar theorem, which is in [5, p. 35]. Let $v \in U$ and let us define $w=v-g$. Lemma 2.2 yields that there exists a sequence of functions $\left\{w_{n}\right\} \subset C^{\infty}(\bar{\Omega}), w_{n}=0$ on $\Omega_{\frac{2}{n}}$ and $w_{n} \rightarrow w$ in the space $H^{1}(\Omega)$.

The function $g$, which is continuous and piecewise linear in $\bar{\Omega}$, can be easily continuously extended onto $\mathbb{R}^{2}$. The functions $w_{n} \in C^{\infty}(\bar{\Omega})$ can also be continuously extended onto $\mathbb{R}^{2}$ by Calderon's extension (cf. $\left[11\right.$, p.80]), since $C^{\infty}(\bar{\Omega}) \subset H^{2}(\Omega)$. We denote the extended functions by the same symbols.

Let us define functions

$$
\hat{w}_{n}=\max \left(-g, w_{n}\right) .
$$

Obviously, $\hat{w}_{n} \in C\left(\mathbb{R}^{2}\right), \hat{w}_{n} \geqslant-g$ and $\hat{w}_{n}=0$ on $\Omega_{\frac{2}{n}}$. Since $w=\max (-g, w)$, Lemma 3.5 implies that $\hat{w}_{n} \rightarrow w$ in the space $H^{1}(\Omega)$. 
Now let us fix $n$ and make the regularization of $\hat{w}_{n}$. We choose $\varrho \in\left(0, \frac{1}{n}\right)$. The functions $R_{\varrho} \hat{w}_{n}$ vanish on $\Omega_{\frac{1}{n}}$, they are from $C^{\infty}\left(\mathbb{R}^{2}\right)$ and by Lemma 3.6

$$
\lim _{\varrho \rightarrow 0}\left\|\hat{w}_{n}-R_{\varrho} \hat{w}_{n}\right\|_{C(\bar{\Omega})}=0
$$

From here and (3.4) it follows that for every $\varepsilon>0$ there exists a sufficiently small $\varrho_{0}(\varepsilon) \in\left(0, \frac{1}{n}\right)$ such that for all $\varrho \in\left(0, \varrho_{0}\right)$ the inequality

$$
-g-\varepsilon \leqslant \hat{w}_{n}-\varepsilon<R_{\varrho} \hat{w}_{n}<\hat{w}_{n}+\varepsilon
$$

holds in $\bar{\Omega}$. In the domain $\Omega$, put

$$
w_{n}^{\varepsilon}=R_{\varrho} \hat{w}_{n}+\varepsilon \theta_{\frac{1}{n}}
$$

where $\theta_{\frac{1}{n}}$ is the function from Lemma 3.3. Then $w_{n}^{\varepsilon} \in C^{\infty}(\bar{\Omega}), w_{n}^{\varepsilon}=0$ on $\Omega_{\frac{1}{2 n}}$, and from (3.6), (3.7) and (3.5) we have

$$
\begin{gathered}
w_{n}^{\varepsilon} \geqslant-g, \\
\lim _{\varepsilon \rightarrow 0}\left\|\hat{w}_{n}-w_{n}^{\varepsilon}\right\|_{1,2}=0 .
\end{gathered}
$$

Since $C^{\infty}(\bar{\Omega}) \subset H^{2}(\Omega)$, Theorem 3.2 implies that $\lim _{h \rightarrow 0}\left\|w_{n}^{\varepsilon}-\pi_{h} w_{n}^{\varepsilon}\right\|_{1,2}=0$.

According to (3.8), the function $\pi_{h} w_{n}^{\varepsilon}+g \in H^{1}(\Omega)$ is non-negative and, moreover, it is clearly $\pi_{h} w_{n}^{\varepsilon}+g=g$ on $\Gamma_{1}$. Therefore $\pi_{h} w_{n}^{\varepsilon}+g \in U_{h}$. Obviously,

$$
\begin{aligned}
& \left\|v-\left(\pi_{h} w_{n}^{\varepsilon}+g\right)\right\|_{1,2}=\left\|w+g-\pi_{h} w_{n}^{\varepsilon}-g\right\|_{1,2} \\
& \leqslant\left\|w-\hat{w}_{n}\right\|_{1,2}+\left\|\hat{w}_{n}-w_{n}^{\varepsilon}\right\|_{1,2}+\left\|w_{n}^{\varepsilon}-\pi_{h} w_{n}^{\varepsilon}\right\|_{1,2} .
\end{aligned}
$$

The last three norms tend to zero, since we have already proved that

$$
\begin{aligned}
& \hat{w}_{n} \rightarrow w \quad \text { as } n \rightarrow \infty, \\
& w_{n}^{\varepsilon} \rightarrow \hat{w}_{n} \quad \text { as } \varepsilon \rightarrow 0 \text { for any } n=1,2, \ldots \\
& \pi_{h} w_{n}^{\varepsilon} \rightarrow w_{n}^{\varepsilon} \quad \text { as } h \rightarrow 0 \text { for any } n=1,2, \ldots \text { and any } \varepsilon>0 .
\end{aligned}
$$

We see that a family of triangulations $\mathscr{F}$ which fulfils the maximum angle condition, allows for sufficiently small $h$ a very precise approximation of a function $v \in U$ by an appropriate function from the space $U_{h}$. 
Theorem 3.8. Let $\Omega \subset \mathbb{R}^{2}$ be a polygonal domain with a Lipschitz boundary. Let $\mathscr{F}$ be a family of triangulations which fulfils the maximum angle condition, and let (3.2) hold. Then the functions $u_{h}$ which are the solutions of the problems (3.3) satisfy

$$
\lim _{h \rightarrow 0}\left\|u_{0}-u_{h}\right\|_{1,2}=0
$$

where $u_{0}$ is the weak solution of (1.1)-(1.2).

Proof. From Theorem 3.7 we know that there exists a sequence $v_{h} \in U_{h}$ such that $\lim _{h \rightarrow 0}\left\|u_{0}-v_{h}\right\|_{1,2}=0$. Evidently, it is $\Pi\left(u_{0}\right) \leqslant \Pi\left(u_{h}\right) \leqslant \Pi\left(v_{h}\right)$. Since $\Pi$ is continuous, we have

$$
\lim _{h \rightarrow 0} \Pi\left(u_{h}\right)=\Pi\left(u_{0}\right)
$$

Taylor's expansion of II yields that

$$
\Pi\left(u_{h}\right)=\Pi\left(u_{0}\right)+\mathrm{D} \Pi\left(u_{0} ; u_{h}-u_{0}\right)+\frac{1}{2} \mathrm{D}^{2} \Pi\left(u_{0}+\theta_{h}\left(u_{h}-u_{0}\right) ; u_{h}-u_{0}, u_{h}-u_{0}\right),
$$

where $\theta_{h} \in(0,1)$. From (1.8) it is easy to derive that for an arbitrary $v \in U$ and $w \in H^{1}(\Omega)$ we have

$$
\mathrm{D}^{2} \mathrm{\Pi}(v ; w, w)=a(w, w)+4 \int_{\Gamma_{2}} \beta v^{3} w^{2} \mathrm{~d} s \geqslant C\|w\|_{1,2}^{2}
$$

where $C$ is a positive constant independent of $v$. In the last inequality we have used the Friedrichs inequality for the first term and neglected the second term, because it is non-negative. So we have

$$
\Pi\left(u_{h}\right)-\Pi\left(u_{0}\right)-\operatorname{DII}\left(u_{0} ; u_{h}-u_{0}\right) \geqslant C\left\|u_{h}-u_{0}\right\|_{1,2}^{2} .
$$

From the definition of the weak solution we know that

$$
\operatorname{D\Pi }\left(u_{0} ; u_{h}-u_{0}\right) \geqslant 0 \text {. }
$$

Using (3.10), (3.9) and (3.11), we obtain

$$
\left\|u_{h}-u_{0}\right\|_{1,2} \rightarrow 0
$$


Theorem 3.9. Let $\Omega \subset \mathbb{R}^{2}$ be a polygonal domain with a Lipschitz boundary. Let $\mathscr{T}$ be a system of triangulations which fulfils the maximum angle condition, and let (3.2) hold. Let the weak solution $u_{0}$ of (1.1)-(1.2) be from the space $H^{2}(\Omega)$ and let there exist a constant $C_{u_{0}}$ such that $u \geqslant C_{u_{0}}>0$ holds in $\Omega$. Then

$$
\left\|u_{0}-u_{h}\right\|_{1,2} \leqslant C h \quad \text { for } h \rightarrow 0
$$

where $u_{h}$ solve (3.3) and $C>0$ is a constant depending only on $u_{0}$.

Proof. As well as in the proof of Theorem 2.3 the condition $u_{0} \geqslant C_{u_{0}}$ ensures the validity of (2.2) for any $v \in V$. Using this relation, we can easily verify that

$$
\Pi\left(u_{0}+v\right)-\Pi\left(u_{0}\right)=\frac{1}{2} a(v, v)+\int_{\Gamma_{2}} \beta\left(2 u_{0}^{3} v^{2}+2 u_{0}^{2} v^{3}+u_{0} v^{4}+\frac{1}{5} v^{5}\right) \mathrm{d} s
$$

for every $v \in V$. The integrals over $\Gamma_{2}$ can be estimated with help of Hölder's integral inequality and Theorem 1.1. So we obtain

$$
\Pi\left(u_{0}+v\right)-\Pi\left(u_{0}\right) \leqslant C \cdot\|v\|_{1,2}^{2} \quad \forall v \in V,\|v\|_{1,2} \leqslant 1
$$

where $C^{\prime}>0$ is a constant depending only on $u_{0}$.

If $u_{0} \in H^{2}(\Omega)(\subset C(\bar{\Omega})$, cf. [11, p. 72]), then thanks to (3.2) it is possible to define $\pi_{h} u_{0} \in U_{h}$. Since $u_{h}$ solve $(3.3)$, we have

$$
\Pi\left(u_{h}\right) \leqslant \Pi\left(\pi_{h} u_{0}\right) .
$$

Then the relations (1.7), (3.10), (3.13), (3.12) and Theorem 3.2 imply

$$
\begin{aligned}
C_{1}\left\|u_{h}-u_{0}\right\|_{1,2}^{2} & \leqslant C_{1}\left\|u_{h}-u_{0}\right\|_{1,2}^{2}+\operatorname{DII}\left(u_{0} ; u_{h}-u_{0}\right) \leqslant \operatorname{\Pi I}\left(u_{h}\right)-\Pi\left(u_{0}\right) \\
& \leqslant \Pi\left(\pi_{h} u_{0}\right)-\Pi\left(u_{0}\right) \leqslant C_{2}\left\|\pi_{h} u_{0}-u_{0}\right\|_{1,2}^{2} \leqslant C_{3} h^{2}\left|u_{0}\right|_{2,2}^{2},
\end{aligned}
$$

where $C_{1}, C_{2}, C_{3}>0$ are constants independent of $h$. 


\section{References}

[1] Carrier G.F., Pearson C.E.: Partial differential equations. Theory and technique, Academic Press, London, 1976.

[2] Ciarlet P.G.: Optimisation, théorie et algorithmes, Dunod, Paris, 1971.

[3] Delfour M.C., Payre G., Zolésio J.P.: Approximation of nonlinear problems associated with radiating bodies in the space, SIAM J. Numer. Anal. 24 (1987), 1077-1094.

[4] Doktor P.: On the density of smooth functions in certain subspaces of Sobolev spaces, Comment. Math. Univ. Carolin. 14 (1973), 609-622.

[5] Glowinski R.: Lectures on numerical methods for nonlinear variational problems, Tata Inst. of Fundamental Research, Bombay, 1980.

[6] Hottel A.C., Sarofim A.F.: Radiative transport, McGraw Hill, New York, 1965.

[7] Jarušek $J .:$ On the regularity of solutions of a thermoelastic system under noncontinuous heating regimes, Apl. Mat. 35 (1990), 426-450.

[8] Kŕżzek M.: On semiregular families of triangulations and linear interpolation, Appl. Math. 36 (1991), 223-232.

[9] Kŕżżek M., Neittaanmäki P.: Finite element approximation of variational problems and applications, Longman, Harlow, 1990.

[10] Na T.Y.: Computational methods in engineering boundary value problems, Academic Press, London, 1979, pp. 231,232,279.

[11] Nečas J.: Les méthodes directes en théorie des equations elliptiques, Academia, Prague, 1967.

[12] Ohayon R., Gorge Y.: Variational analysis of a non-linear non-homogeneous heat conduction problem, Proc. Conf. Numerical Methods for Non-linear Problems, Swansea 1980, Pineridge Press, Swansea, 1980, pp. 673-681.

[13] Olmstead W.E.: Temperature distribution in a convex solid with a nonlinear radiation boundary condition, J. Math. Mech. 15 (1966), 899-907.

[14] Szabó B.A., Babuskka I.: Finite element analysis, John Wiley \& Sons, New York, 1991.

[15] Vujanovič B., Djukič D.: On the variational principle of Hamilton's type for nonlinear heat transfer problem, Internat. J. Heat Mass Transfer (1972), 1111-1123.

[16] Vujanovič B., Strauss A.M.: Heat transfer with nonlinear boundary conditions via a variational principle, AIAA (1971), 327-330.

Souh r

\section{ŘEŠENÍ STACIONÁRNÍ ÚLOIIY VEDENÍ TEPLA S OKRAJOVOU PODMÍNKOU SÁLÁNÍ METODOU KONEČNÝCH PRVKÜ}

\section{ZDENĚK MILKA}

V článku je uvedena variační formulace stacionární úlohy vedení tepla s okrajovými podmínkami vedení a sálání. Je dokázána existence a jednoznačnost řešení. Dále je úloha řešena metodou lineárních konečných prvků. Je ukázána konvergence přibližných řešení k přesnému a je zkoumána i rychlost této konvergence při jistých požadavcích na hladkost přesného řešení.

Author's address: Zdeněk Milka, Matematický ústav ČAV, Žitná 25, 11567 Praha 1, Czech Republic. 